\title{
Importance of Intrinsic and Extrinsic Attributes of Cheese during the Buying Decision Process
}

\author{
Gabriela CHICIUDEAN*, Sabina FUNAR and Iulia MUREŞAN \\ University of Agricultural Sciences and Veterinary Medicine Cluj-Napoca, Faculty of Horticulture, Calea \\ Mănăştur 3-5, 400372, Cluj-Napoca, Cluj, Romania \\ *)Corresponding author, e-mail: gabriela_chirla@yahoo.com
}

BulletinUASVM Horticulture 73(1) / 2016

Print ISSN 1843-5254, Electronic ISSN 1843-5394

DOI:10.15835/buasvmcn-hort:11493

\begin{abstract}
In the agro-food sector some customers adopt their buying decision based only on extrinsic attributes (brand, package, label etc.) others take into consideration just intrinsic attributes (taste, ingredients etc.). The aim of this study is to determine which attributes (extrinsic or intrinsic) are more important for customers during the buying decision process for cheese. In order to achieve the goal of this study, a survey was conducted among the population form Cluj-Napoca on a sample of 216 respondents. Results indicate that in the case of cheese products, customers are more interested in the intrinsic attributes ("taste", "made from natural ingredients", "aspect") than in the extrinsic ones ("recyclable package" or "resalable package"). It can be concluded that the attributes mostly preferred by customers during the buying decision process are useful to determine the type of strategies that companies should adopt: strategies based on food research and recipes or by the contrary, marketing strategies for improving packaging, image and brand.
\end{abstract}

Keywords: taste, natural ingredients, marketing strategies.

\section{INTRODUCTION}

For each company is very important to investigate the way the customers evaluate their products based on different cues (attributes). The difference between the two types of attributes refers to the fact that the extrinsic attributes are applicable to all kinds of products while the intrinsic ones are related to a particular product (Lee and Lou, 2011). Intrinsic cues define the products' physical aspects while the extrinsic cues are related to the product itself without being a part of it (Bernues et al., 2003; Fandos and Flavian, 2006). In the agro-food sector some customers adopt their buying decision based only on extrinsic attributes (brand, package, label etc.) others take into consideration just the intrinsic ones (taste, ingredients etc.) (Felipe et al., 2012). Sometimes quality judgements referring to a cheese product may be influenced by visual elements or by the attractiveness of a label (Veale et al., 2006). Therefore, marketers must understand the evaluating process from the consumers' mind in order to adopt the correct decisions.

\section{AIMS}

The aim of this study is to determine which attributes (extrinsic or intrinsic) are more important for customers during the buying decision process for cheese. The research is useful for companies because the marketers could adopt adequate strategies (based on intrinsic or extrinsic cues) in order to increase the sales.

\section{MATERIALS AND METHODS}

To achieve the goal of this study, a survey was conducted in 2012 among the households form Cluj-Napoca on a representative sample of 216 respondents, determined using Taro-Jamain relation: $\quad \mathrm{n}=\mathrm{N} /\left(1+\mathrm{N}^{*} \mathrm{e}^{2}\right)=119.378 /(119.378 /$ $\left(1+119.378^{*} 0.07^{2}\right)=204$, where " $n$ " represents the sample size, "N" represents the total population and " $\mathrm{e}$ " is the maximum admitted error. To assure the representativeness of the sample, number of 256 questionnaires were distributed, from which 216 were validated for future analysis. The sample units were selected randomly based on their custom of buying process cheese. The instrument 
used was the questionnaire which comprised five parts. In the first section of the questionnaire respondents are demanded to give grades from 0-10 for a set of intrinsic and extrinsic attributes of cheese depending of how important each attribute is, during the buying decision process. The ranking method was implied using meanvalues for each cue (Johansen et al., 2011). The cues were extracted from other researches related to cheese during a one month of literature review.

\section{RESULTS AND DISCUSSION}

Results indicate that in the case of cheese products, customers consider that intrinsic cues such as "taste" (9.35) and "natural ingredients" (8.67) are the most important attributes during the decision-making process. The least important intrinsic attribute in the case of cheese is the "low fat content" (6.25). The results are similar to a cross-cultural study conducted in Norway, Denmark and California by (Johansen et al., 2011) were attributes like "healthiness" and "taste" were the most important motivators for choice in the case of dairy products. The major difference refers to the attribute "fat content" which is the least important attribute for Romanian consumers, while in the three countries mentioned above, is one of the most important one. The most important extrinsic cues during the decision-making process for cheese are "quality sign" and "information on the label" (8.29), followed by "attractive shape" (8.08), and "brands' reputation" (7.96) while the least important attribute is "recyclable package" (4.25). Analysing the mean values obtained for each cue it can be noticed that the intrinsic ones are more important to consumers which pay attention to healthy products based on natural ingredients. The high score obtained by the "quality sign" indicates that consumers have more trust in labelled products and certified products. Packaging is not important at all for cheese consumers.

\section{CONCLUSION}

It can be concluded that the attributes mostly preferred by Romanian consumers from Cluj County during the buying decision process for cheese are mostly intrinsic (taste, fat content, natural ingredients) being the most import indicators of a quality product so, the type of strategies that companies should adopt must rely mainly on food research and recipes and less on marketing strategies of packaging, image and brand. Marketing strategies which deal with extrinsic cues are also important to the extent of increasing the marketing value of cheese, because consumers are interested in buying cheese products with quality signs, pay attention to labels and adopt their buying decision based on brand reputation. Therefore, dairy industry should focus mainly on improving recipes, buying quality raw materials and ensure a healthy product without artificial ingredients. The research findings are important to the dairy industry, mainly from a practical point of view because it indicates the type of strategies the companies should focus on, in order to gain consumer preference. This was an exploratory research meant to determine which are the main attributes that Romanian consumers appreciate when they decide to buy processed cheese and to evidence which are the main differences between them and consumers from other countries. The research represents a first stage for such studies on Romanian dairy products.

\section{REFERENCES}

1. Bernue A, Olaizolab A, Corcoranc K (2003). Extrinsic attributes of red meat as indicators of quality in Europe: an application for market segmentation. Food Quality and Preference 14:265-276.

2. Fandos C, Flavian C (2006). Intrinsic and extrinsic quality attributes loyalty and buying intention: an analysis for a PDO product. British Food Journal, 108(8):646-662.

3. Johansen SB, Naes T, Hersleth M (2011). Motivation for choice and healthiness perception of calorie-reduced dairy products. A cross-cultural study. Appetite 56:15-24.

4. Lee M., Lou YC (2011). Consumer Reliance on Intrinsic and Extrinsic Cues in Product Evaluations: A Conjoint Approach. Journal of Applied Business Research. 12(1):22-29.

5. Felipe J, Guerrero J, Gázquez-Abad JC, Mondéjar-Jiménez JA, García RH (2012). Consumer Preferences for Olive-Oil Attributes: A Review of the Empirical Literature Using a Conjoint Approach. Olive Oil - Constituents, Quality, Health Properties and Bioconversions. 233-246.

6. Veale R, Pascale Q, Karunaratna A (2006). The role of intrinsic (sensory) cues and the extrinsic cues of country of origin and price on food product evaluation. $3^{\text {rd }}$ International Wine Business \& Marketing Research Conference, Montpellier. 